\title{
Erratum: Continuous subcutaneous hydrocortisone infusion in Addison's disease
}

Kristian Løvås ${ }^{1,2}$ and Eystein S Husebye ${ }^{1,2}$

${ }^{1}$ Division of Endocrinology, Institute of Medicine, University of Bergen and ${ }^{2}$ Department of Medicine, Haukeland University Hospital, 5021 Bergen, Norway

(Correspondence should be addressed to K Løvås; Email: kristian.lovas@med.uib.no)

The authors and the journal apologize for an error in the above paper which appeared in 157 (1) (109-112). In this paper on page 110, the hydrocortisone doses given in Fig. 1A were incorrect. The correct hydrocortisone doses were $0.5(08-12 \mathrm{~h}), 0.2(12-20 \mathrm{~h}), 0.05(20-02 \mathrm{~h})$ and $1.0 \mathrm{mg} / \mathrm{m}^{2}$ body surface area/hour (02-08 h).

European Journal of Endocrinology 158939 